\title{
GENDER DIFFERENCES IN RELATION TO HOFSTEDE'S NATIONAL CULTURAL DIMENSIONS
}

\author{
Gylfi Dalmann Adalsteinsson, University of Iceland, Reykjavik, Iceland \\ Svala Gudmundsdottir, University of Iceland, Reykjavik, Iceland \\ Thorhallur Gudlaugsson, University of Iceland, Reykjavik, Iceland
}

dx.doi.org/10.18374/JIMS-13-3.9

\begin{abstract}
This study provides an exploratory examination of gender differences in cultural characteristics within the Icelandic culture. Hofstede's framework is applied as it has received great attention from business scholars for decades. More recently increased attention has been given to the gender difference found in this model. The research question is: What is the gender difference within Hofstede's five cultural dimensions in Iceland? Participants were 427 undergraduate students at the University of Iceland. The five dimensions of national culture were measured using a scale developed by Hofstede (1994) called VSM94. The findings of this study reveal a considerable difference in relation to gender, particularly on the Masculinity/femininity dimension where women rate the culture as being more feminine than men do.
\end{abstract}

Keywords: Hofstede's Cultural Dimensions, Gender Gap, Workforce Participation in Iceland. 